\title{
Rendimento, valor nutritivo e características fermentativas de silagens de cereais de inverno
}

\author{
Yield, nutritive value and fermentative parameters of winter cereals silages
}

\author{
Rosilene Inês Lehmen ${ }^{\mathrm{I}}$ Renato Serena Fontaneli ${ }^{\mathrm{II}}$ Roberto Serena Fontaneli ${ }^{\mathrm{II}}$ \\ Henrique Pereira dos Santos ${ }^{\text {II }}$
}

\section{RESUMO}

O experimento foi conduzido para avaliar o rendimento de forragem, valor nutritivo e a qualidade fermentativa de silagens de cereais de inverno. Foram avaliados doze genótipos de gramíneas anuais de inverno: aveias brancas: URS 21, URS Guapa e Barbarasul; trigos: BRS Tarumã e BRS Umbu; triticales: Embrapa 53 e BRS Minotauro; centeio: BRS Serrano; cevada: BRS Cauê; e aveias pretas: BRS 139-Neblina, IAPAR 61-Ibiporã e Ucrânia. A ensilagem foi realizada no estádio de grão pastoso a massa firme, com 30 a 35\% de matéria seca, e armazenada em silos experimentais de PVC, por 90 dias, para avaliação. $O$ delineamento foi em blocos casualizados, com três repetições. Todos os genótipos avaliados apresentaram características satisfatórias para ensilagem. O centeio BRS Serrano apresentou maior produção de biomassa ensilável, enquanto a cevada BRS Cauê, o trigo BRS Umbu e as aveias brancas UFRGS 19, URS Fapa-Slava e UPF 16 apresentaram os maiores teores de proteína bruta.

Palavras-chave: forragem conservada, nitrogênio amoniacal, $\mathrm{pH}$, proteína bruta.

\section{ABSTRACT}

The study was carried out to evaluate the forage yield for ensilage, nutritive value and fermentative parameters for winter cereals silages. It was evaluated twelve winter annual grasses genotypes: white oat URS 21, URS Guapa and Barbarasul, wheat BRS Tarumã and BRS Umbu, triticale Embrapa 53 and BRS Minotauro, rye BRS Serrano, barley BRS Cauê and black oat BRS 139-Neblina, IAPAR 61-Ibiporã and Ucrânia. The genotypes were ensiled at dough grain to firm mass stages, with 30 at 35\% dry matter, and packaged, for ninety days, in PVC experimental silos. The design was a randomized complete block, with three replications. All genotypes evaluated present satisfactory characteristics for ensilage. The BRS Serrano rye presented greater biomass yield. The BRS Caue barley, BRS Umbu wheat and UFRGS 19, URS Fapa-Slava and UPF 16 white oats present higher crude protein concentrations.

Key words: conserved forage, ammonia nitrogen, $\mathrm{pH}$, crude protein.

\section{INTRODUÇÃO}

A adequada nutrição dos animais ao longo do ano é fundamental, não apenas para a manutenção do peso corporal, como para maiores taxas de ganho de peso, produção de leite, sanidade e eficiência reprodutiva (ANDRADE, 1995; FONTANELI et al., 2011).

Quando são adotados sistemas de produção baseados na utilização de pastagens naturais ou cultivadas, fornecidas através de pastoreio, a produção animal se dá de forma mais prática e econômica. No entanto, devido à estacionalidade de produção de forragens, a adoção exclusiva desses sistemas tornase inviável (JOBIM et al., 2005).

No Sul do Brasil, a estacionalidade é evidente no período do outono, quando a oferta e a qualidade das forragens é baixa, pois coincide com o período em que as forrageiras de verão estão findando seu ciclo, enquanto as anuais de inverno estão iniciando. Este período é conhecido como "vazio forrageiro outonal", sendo caracterizado pela perda de peso dos animais e redução na produção leiteira (FONTANELI \& FONTANELI, 2009).

\footnotetext{
IPrograma de Pós-graduação em Agronomia, Universidade de Passo Fundo (UPF), Passo Fundo, RS, Brasil.

*Autor para correspondência.

IIIUniversidade Estadual do Rio Grande do Sul (UERGS), Erechim, RS, Brasil.

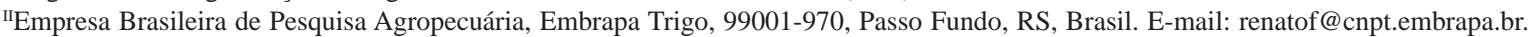


A necessidade de manutenção do peso corporal dos animais e uma produção leiteira estável ao longo do ano tornam imprescindível a busca por alternativas para a alimentação dos animais durante os períodos de escassez de forragem. Uma das alternativas seria a conservação de forragens por meio da ensilagem de cereais de inverno, o que apresenta diversas vantagens, como a redução dos riscos da falta de alimentos ocasionada por intempéries, produção de grãos nos cultivos de verão destinados à alimentação humana, evitando-se a competição destes cultivos com o uso para ensilagem (BUMBIERIS JR. et al., 2011), possibilidade de utilização dos cereais de inverno para pastoreio antes da ensilagem, bem como a ensilagem do excedente de forragem destinada inicialmente apenas ao pastoreio e a utilização de áreas que costumam ficar ociosas durante o inverno. Segundo MORAES et al., (2011), no Sul do Brasil, 12,8 milhões de hectares ficam praticamente sem renda durante o inverno. Dessa forma, a utilização de cereais de inverno para ensilagem possibilita aumento na geração de renda das propriedades, além de resultar em aumento na eficiência de uso das terras.

Assim, objetivou-se avaliar o rendimento de forragem, o valor nutritivo e as características fermentativas dos cereais de inverno para ensilagem.

\section{MATERIAL E MÉTODOS}

O experimento foi conduzido em área pertencente a Embrapa Trigo, localizada no município de Passo Fundo - RS, região fisiográfica do Planalto Médio. A área é definida pelas coordenadas $28^{\circ} 15$ ' de latitude Sul e $52^{\circ} 24^{\prime}$ de longitude Oeste, em uma altitude de 687 metros acima do nível do mar. O solo da região é classificado como Latossolo Vermelho distrófico húmico (STRECK et al., 2008) e o clima é descrito como subtropical úmido (Cfa), de acordo com a classificação de Köppen. Na tabela 1, é possível observar as condições climatológicas durante a condução do experimento.

A área da parcela foi de 5,0 $\mathrm{m}^{2}$ (5 linhas de $5 \mathrm{~m} \times 0,2 \mathrm{~m}$ ), com os tratamentos dispostos no delineamento experimental em blocos ao acaso, com três repetições.

Os tratamentos foram doze genótipos de gramíneas anuais de inverno, sendo três de aveia branca (Avena sativa L.), URS 21, URS Guapa e Barbarasul; dois de trigo (Triticum aestivum L.), BRS Tarumã e BRS Umbu; dois de triticale (X Triticosecale Wittmack), Embrapa 53 e BRS Minotauro; um de centeio (Secale cereale L.), BRS Serrano; um de cevada (Hordeum vulgare L.), BRS Cauê; e três de aveia preta
(Avena strigosa Schreb.), IAPAR 61-Ibiporã, Embrapa 139-Neblina e Ucrânia.

A semeadura foi realizada no dia 18 de maio de 2011, juntamente com a adubação de $300 \mathrm{~kg} \mathrm{ha}^{-1}$ da formulação 08-24-18 ( $\left.\mathrm{N}-\mathrm{P}_{2} \mathrm{O}_{5}-\mathrm{K}_{2} \mathrm{O}\right)$, com aplicação de ureia em cobertura (45 $\left.\mathrm{kg} \mathrm{N} \mathrm{ha}^{-1}\right) 50$ dias após a semeadura. $\mathrm{O}$ corte para ensilagem foi realizado quando as plantas atingiram o estádio de grão pastoso a massa firme, com aproximadamente 30 a 35\% de matéria seca.

Para ensilagem, foram colhidas as duas linhas centrais de cada parcela, sendo pesados, homogeneizados e retirada uma amostra, para secagem em estufa com ventilação forçada a $60^{\circ} \mathrm{C}$, até peso constante, para determinação do rendimento de forragem ensilável. O restante foi triturado em moinho forrageiro, em fragmentos de 0,5 a $3,0 \mathrm{~cm}$, e compactadas manualmente em silos experimentais de PVC com 100 mm de diâmetro e $40 \mathrm{~cm}$ de altura. Os silos foram acondicionados em local abrigado da luz e calor, sendo abertos para avaliação 90 dias após o fechamento. A altura das plantas foi determinada no momento do corte para ensilagem através de medição com régua graduada.

$\mathrm{Na}$ abertura dos silos, foram desprezadas as porções superior e inferior de silagem de cada silo. O material retirado foi homogeneizado e amostras foram coletadas para avaliação de $\mathrm{pH}$, nitrogênio amoniacal e teor de matéria seca.

A determinação do $\mathrm{pH}$ foi realizada utilizando-se metodologia descrita por SILVA \& QUEIROZ (2002) e a leitura, por meio de potenciômetro digital. Para determinação do teor de nitrogênio amoniacal foi utilizada metodologia descrita por RECH et al. (2006). Para determinação do teor de matéria seca, foram utilizadas amostras secas em estufa de ventilação forçada a $60^{\circ} \mathrm{C}$, até que atingissem peso constante.

Para análise do valor nutritivo das silagens, foram utilizadas amostras previamente secas em estufa de ventilação forçada a $60^{\circ} \mathrm{C}$, até peso constante. $\mathrm{O}$ material foi triturado em moinho do tipo Willey, peneira com malha de 1,0 mm, e retirada sub-amostra para determinação dos teores de proteína bruta (PB), fibra insolúvel em detergente neutro (FDN), fibra insolúvel em detergente ácido (FDA) e digestibilidade estimada da matéria seca (DMS) pelo método de reflectância do infravermelho proximal - NIRS, descrito por FONTANELI \& FONTANELI (2007).

Os dados das variáveis resposta altura de planta, rendimento e teor de matéria seca, $\mathrm{pH}$, nitrogênio amoniacal e teores de PB, FDN, FDA e digestibilidade foram submetidos à análise de variância para o modelo em blocos casualizados e, 
Tabela 1 - Dados climatológicos de temperatura, precipitação e insolação, ocorridas e normais, durante o período de condução do experimento (maio a outubro de 2011). Passo Fundo, RS.

\begin{tabular}{|c|c|c|c|c|c|c|}
\hline \multirow{2}{*}{ Mês/2011 } & \multicolumn{2}{|c|}{-----------Temperatura $\left({ }^{\circ} \mathrm{C}\right)$---------- } & \multicolumn{2}{|c|}{---------Precipitação (mm)----------- } & \multicolumn{2}{|c|}{-------Insolação (horas) ------ } \\
\hline & Média Ocorrida & Média Normal & Ocorrida & Normal & Ocorrida & Normal \\
\hline Maio & 14,1 & 15,2 & 137,1 & 114,3 & 181,3 & 181,1 \\
\hline Junho & 11,4 & 12,9 & 226,7 & 133,6 & 129,3 & 153,7 \\
\hline Julho & 12,4 & 13,3 & 340,0 & 161,8 & 151,9 & 162,6 \\
\hline Agosto & 13,4 & 13,9 & 254,4 & 187,8 & 154,1 & 161,1 \\
\hline Setembro & 15,4 & 15,7 & 47,3 & 197,7 & 196,6 & 154,9 \\
\hline Outubro & 18,3 & 17,6 & 194,7 & 152,9 & 254,0 & 202,3 \\
\hline
\end{tabular}

Fonte: EMBRAPA - CNPT.

quando necessário, as médias foram comparadas pelo teste de Duncan $(\mathrm{P}>0,05)$, utilizando-se o pacote estatístico SAS, versão 8.2 (SAS, 2003).

\section{RESULTADOS E DISCUSSÃO}

Por meio dos resultados obtidos, é possível observar que os genótipos avaliados são de ciclos (da emergência até o corte para ensilagem) distintos, com cultivares precoces, intermediários e tardios. A cultivar mais precoce para ensilagem, com 139 dias de ciclo, foi a cevada BRS Cauê (Tabela 2). Já os genótipos mais tardios foram centeio BRS Serrano e a aveia preta Ucrânia, com 170 dias de ciclo (Tabela 2).

A altura das plantas também diferiu entre os genótipos. O centeio BRS Serrano apresentou a maior altura, atingindo 160 cm, já a cevada BRS Cauê apresentou altura de $56 \mathrm{~cm}$, a menor entre os genótipos avaliados (Tabela 2).

Em ensaio de cultivares de aveia branca realizado em Guarapuava/PR, por ALMEIDA \& FOSTIM (2011), os valores de estatura foram superiores aos obtidos no experimento para os genótipos de aveia branca avaliados, o que pode ter contribuído para a não ocorrência de acamamento, visto que plantas altas tendem a acamar em decorrência de ventos ou chuvas fortes.

Houve diferença significativa quanto ao rendimento de forragem ensilável entre os genótipos. O centeio BRS Serrano e a cevada BRS Cauê apresentaram maior e menor rendimentos, respectivamente (Tabela 2). FONTANELI et al. (2009), avaliando cereais de inverno, também observaram altos rendimentos em centeio BRS Serrano (superior 10t MS ha ${ }^{-1}$ ) e baixos rendimentos para a cevada (inferior a 5t MS ha-1), bem como para altura de plantas, com centeio superior a $130 \mathrm{~cm} \mathrm{e}$ cevada inferior a $80 \mathrm{~cm}$.

Além de fatores intrínsecos aos genótipos, o rendimento de biomassa pode estar relacionado ao ciclo de cultivo. Como pode ser observado na tabela 1 , nos meses de junho, julho e agosto, a insolação foi inferior à normalmente ocorrida neste período, o que pode ter favorecido os genótipos com ciclo mais longo, como o centeio, resultando em maior acúmulo de matéria seca.

De acordo com MUCK (1988), os teores ideais de matéria seca de silagens devem estar em torno de 30 a $35 \%$, e associados a valores de $\mathrm{pH}$ inferiores a 5 para que não ocorram fermentações indesejadas pela presença de microrganismos, além de redução da quebra de proteínas na proteólise. Dos genótipos avaliados, alguns resultaram em valores de matéria seca abaixo do desejável, como BRS Cauê, BRS 139-Neblina e IAPAR 61-Ibiporã, com teores de matéria seca entre 28 e 29\% (Tabela 3). No entanto, em todos os genótipos avaliados, os valores de nitrogênio amoniacal estiveram dentro dos parâmetros considerados aceitáveis e associados a adequados valores de $\mathrm{pH}$, abaixo de 5,0, não prejudicando a qualidade final das silagens.

Não houve diferença significativa entre o pH dos genótipos ensilados, estando entre 3,96 e 4,69. No entanto, pôde-se observar diferença entre os genótipos quanto aos teores de matéria seca e nitrogênio amoniacal (Tabela 3).

Os valores de $\mathrm{pH}$ obtidos foram superiores aos observados por MEINERZ et al. (2011), ao avaliarem silagens de cereais de inverno. Segundo FERREIRA (2001), silagens com adequada fermentação devem apresentar valores de $\mathrm{pH}$ entre 3,8 e 4,2 . No entanto, não foi observada nenhuma alteração que indicasse a ocorrência de fermentações indesejadas nas silagens durante a abertura dos silos. 
Tabela 2 - Ciclo, altura das plantas e rendimento de biomassa ensilável de genótipos de cereais de inverno

\begin{tabular}{lccc}
\hline Genótipos & Ciclo* (dias) $^{*}$ & Altura (cm) & Rendimento (kg ha ${ }^{-1}$ MS) \\
\hline CEV BRS Cauê & 139 & $56 \mathrm{~h}$ & $6.500 \mathrm{e}$ \\
AB URS 21 & 142 & $101 \mathrm{def}$ & $9.713 \mathrm{bcd}$ \\
AB URS Guapa & 152 & $96 \mathrm{f}$ & $8.957 \mathrm{~cd}$ \\
AB Barbarasul & 149 & $97 \mathrm{ef}$ & $8.764 \mathrm{~cd}$ \\
AP BRS 139-Neblina & 152 & $123 \mathrm{~b}$ & $9.500 \mathrm{bcd}$ \\
TR BRS Tarumã & 157 & $79 \mathrm{~g}$ & $10.937 \mathrm{~b}$ \\
AP IAPAR 61-Ibiporã & 152 & $120 \mathrm{bc}$ & $8.194 \mathrm{~d}$ \\
TRT Embrapa 53 & 149 & $103 \mathrm{de}$ & $10.284 \mathrm{bc}$ \\
AP Ucrânia & 170 & $116 \mathrm{c}$ & $10.964 \mathrm{~b}$ \\
CEN BRS Serrano & 170 & $160 \mathrm{a}$ & $13.448 \mathrm{a}$ \\
TR BRS Umbu & 152 & $83 \mathrm{~g}$ & $8.688 \mathrm{~cd}$ \\
TRT BRS Minotauro & 152 & $105 \mathrm{~d}$ & $9.859 \mathrm{bcd}$ \\
Médias & 152 & 103,3 & 9.651 \\
CV (\%) & & 3,3 & 10,1 \\
\hline
\end{tabular}

*Período, em dias, entre a emergência das plantas e o corte para ensilagem.

$\mathrm{CEV}=$ cevada, $\mathrm{AB}=$ aveia branca, $\mathrm{AP}=$ aveia preta, $\mathrm{TR}=$ trigo, $\mathrm{TRT}=$ triticale, $\mathrm{CEN}=$ centeio.

Médias seguidas de mesma letra, nas colunas, não diferem significativamente pelo teste de Duncan $(\mathrm{P}>0,05)$.

O teor de nitrogênio amoniacal nas silagens tem sido um parâmetro amplamente utilizado para indicar a ocorrência de processo fermentativo eficiente. Teores de nitrogênio amoniacal inferiores a 10\% do nitrogênio total da silagem indicam uma boa preservação do material, baixa degradação das proteínas e consequente qualidade da silagem (VAN SOEST, 1994; TOMICH et al., 2003).

Todos os genótipos avaliados apresentaram teores de nitrogênio amoniacal dentro dos níveis aceitáveis, indicando baixa proteólise (Tabela 3). As aveias brancas URS 21 e Barbarasul, trigo BRS Umbu, centeio BRS Serrano, triticale Embrapa 53 e aveias pretas BRS 139-Neblina e Ucrânia obtiveram os menores teores de nitrogênio amoniacal.

LOPES et al. (2008), avaliando triticale para ensilagem, obtiveram valores inferiores de pH (pH 3,70 para idade de corte de 118 dias) em comparação às silagens de triticale avaliadas no experimento. No entanto, os valores de nitrogênio amoniacal foram superiores aos aqui observados (nitrogênio amoniacal 13,9 para idade de corte de 118 dias).

Quanto ao valor nutritivo, não houve diferença para os teores de proteína bruta (PB) e fibra insolúvel em detergente neutro (FDN), com valores variando de 6,0 a $8,4 \%$ para $\mathrm{PB}$ e, de 59 a $74 \%$, para FDN (Tabela 4). Houve diferença entre os genótipos para fibra insolúvel em detergente ácido (FDA) e digestibilidade estimada da matéria seca (DMS). A aveia preta IAPAR 61-Ibiporã apresentou o maior valor de FDA e, consequentemente, o menor DMS. Em contraste, o menor valor FDA e o maior de DMS foi apresentado pelo triticale Embrapa 53 (Tabela 4), embora sem diferir do triticale BRS Minotauro, dos trigos e da cevada.

O triticale Embrapa 53 destacou-se por apresentar os menores teores de fibra e a maior digestibilidade estimada da matéria seca (DMS), semelhante ao observado por FONTANELI et al. (2009). A digestibilidade se refere aos nutrientes que serão desdobrados no trato digestório dos animais, durante a digestão, e absorvidos pelo organismo. A digestibilidade sofre grande influência do processo fermentativo. Baixa digestibilidade em silagens pode indicar a ocorrência de alterações durante a fermentação (EVANGELISTA et al., 2004).

Segundo VAN SOEST (1994), o teor de proteína bruta mínimo necessário para o crescimento microbiano do rúmen é de $7 \%$, caso contrário, a fermentação ruminal é prejudicada, além de incorrer na diminuição do consumo do alimento pela baixa concentração de proteína. Dentre os genótipos avaliados, embora a média geral foi de $7,3 \%$, não cumpririam este requisito em valores absolutos as aveias pretas Embrapa 139-Neblina, IAPAR 61-Ibiporã e Ucrânia, além do centeio BRS Serrano (Tabela 4).

COAN et al. (2001), avaliando silagens de forrageiras de inverno, obtiveram valores de proteína bruta média de $10 \%$, sendo superiores aos resultados obtidos neste experimento, em que o valor máximo de proteína bruta obtido foi de 8,7\%. Os mesmos 
Tabela 3 - Teores de matéria seca (MS), pH e nitrogênio amoniacal (N-NH$)$ das silagens de cereais de inverno.

\begin{tabular}{llll}
\hline Genótipos & MS (\%) & pH & N-NH $(\%$ Nitrogênio total) \\
\hline CEV BRS Cauê & 28,36 b & 4,43 ab \\
AB URS 21 & 28,21 b & 3,99 e & 7,01 abc \\
AB URS Guapa & $33,94 \mathrm{a}$ & 3,96 & 3,93 e \\
AB Barbarasul & 27,74 b & 4,44 & 4,94 cde \\
AP BRS 139-Neblina & 29,66 b & 4,20 & 6,73 abcd \\
TR BRS Tarumã & 33,99 a & 4,25 & 9,11 a \\
AP IAPAR 61-Ibiporã & 28,55 b & 4,23 & 6,22 bcde \\
TRT Embrapa 53 & 34,07 a & 4,48 & 4,52 de \\
AP Ucrânia & 33,85 a & 4,59 & 4,38 de \\
CEN BRS Serrano & 33,69 a & 4,31 & 5,91 bcde \\
TR BRS Umbu & 33,78 a & 4,26 & 7,13 abc \\
TRT BRS Minotauro & 33,51 a & 4,14 & 5,94 \\
Médias & 31,61 & 3,98 & 17,1 \\
CV (\%) & 4,9 & 4,29 & 4,9 \\
\hline
\end{tabular}

$\mathrm{CEV}=$ cevada, $\mathrm{AB}=$ aveia branca, $\mathrm{AP}=$ aveia preta, $\mathrm{TR}=$ trigo, $\mathrm{TRT}=$ triticale, $\mathrm{CEN}=$ centeio.

Médias seguidas de mesma letra, nas colunas, não diferem significativamente pelo teste de Duncan $(\mathrm{P}>0,05)$.

autores também obtiveram valores inferiores de FDN, mas os valores de FDA foram semelhantes aos obtidos no experimento. FONTANELI et al. (2009) obtiveram valores de proteína bruta superiores a 7\% em todos os genótipos avaliados, sendo superiores, em sua maioria, aos valores obtidos neste trabalho. Como pode ser observado na tabela 1 , a precipitação ocorrida no mês de setembro foi inferior à precipitação normal observada nos anos anteriores. Esse fato pode ter contribuído para acelerar o processo de maturação das plantas e, dessa forma, resultar em redução dos teores de proteína das silagens avaliadas.

\section{CONCLUSÃO}

Todos os genótipos avaliados têm características que possibilitam fermentações para conservação de forragem na forma de silagem. A cevada BRS Cauê é o genótipo mais precoce e de menor rendimento para ensilagem, enquanto o centeio

Tabela 4 - Teores de proteína bruta (PB), fibra insolúvel em detergente neutro (FDN), fibra insolúvel em detergente ácido (FDA) e digestibilidade estimada da matéria seca (DMS) de silagens de cereais de inverno.

\begin{tabular}{|c|c|c|c|c|}
\hline & PB & FDN & FDA & DMS \\
\hline CEV BRS Cauê & 8,4 & 59,6 & 30,7 bcd & $64,9 \mathrm{abc}$ \\
\hline AB URS 21 & 7,6 & 64,1 & 37,0 abc & 60,1 bcd \\
\hline AB URS Guapa & 7,3 & 66,5 & 38,9 abc & 58,6 bcd \\
\hline AB Barbarasul & 7,3 & 66,0 & 37,6 abc & 59,6 bcd \\
\hline AP BRS 139-Neblina & 6,0 & 74,3 & $43,4 \mathrm{ab}$ & $55,1 \mathrm{~cd}$ \\
\hline TR BRS Tarumã & 8,0 & 65,4 & 33,8 abcd & $62,6 \mathrm{abcd}$ \\
\hline AP IAPAR 61-Ibiporã & 6,5 & 74,7 & $46,0 \mathrm{a}$ & $53,1 \mathrm{~d}$ \\
\hline TRT Embrapa 53 & 7,9 & 56,5 & $22,3 \mathrm{~d}$ & $71,5 \mathrm{a}$ \\
\hline AP Ucrânia & 6,2 & 65,1 & $37,1 \mathrm{abc}$ & 60,0 bcd \\
\hline CEN BRS Serrano & 6,8 & 73,7 & $40,4 \mathrm{abc}$ & 57,5 bcd \\
\hline TR BRS Umbu & 8,3 & 62,4 & 30,6 bcd & $65,1 \mathrm{abc}$ \\
\hline TRT BRS Minotauro & 7,9 & 63,2 & $28,9 \mathrm{~cd}$ & $66,4 \mathrm{ab}$ \\
\hline Médias & 7,3 & 65,9 & 35,55 & 61,2 \\
\hline CV (\%) & 13,5 & 8,1 & 14,6 & 6,6 \\
\hline
\end{tabular}

$\mathrm{CEV}=$ cevada, $\mathrm{AB}=$ aveia branca, $\mathrm{AP}=$ aveia preta, $\mathrm{TR}=$ trigo, $\mathrm{TRT}=$ triticale, $\mathrm{CEN}=$ centeio.

Médias seguidas de mesma letra, nas colunas, não diferem significativamente pelo teste de Duncan $(\mathrm{P}>0,05)$. 
BRS Serrano é o destaque quanto a rendimento de matéria seca. Considerando-se rendimento e valor nutritivo, indica-se ensilar as cultivares de trigo BRS Tarumã e BRS Umbu, além dos triticales Embrapa 53 e BRS Minotauro.

\section{REFERÊNCIAS}

ALMEIDA, J.L.; FOSTIM, M.L. Ensaio brasileiro de cultivares recomendados de aveia 2010 FAPA, Guarapuava, PR. In: REUNIÃO DA COMISSÃO BRASILEIRA DE PESQUISA DE AVEIA, 31., 2011, Passo Fundo, RS. Resultados experimentais... Passo Fundo: RCBPA, 2011. p.430-433.

ANDRADE, P. Alimentação de bovinos em épocas críticas. In: PEIXOTO, A.M. et al. Nutrição de bovinos - Conceitos básicos e aplicados. 5.ed. Piracicaba: FEALQ, 1995. V.7, p.239-250.

BUMBIERIS JR, V.H. et al. Use of winter cultures for forage conservation. In: DANIEL, J.L.P. et al. Forage quality and conservation. INTERNATIONAL SYMPOSIUM ON FORAGE QUALITY AND CONSERVATION, 2., 2011, São Pedro, SP. Anais... Piracicaba: FEALQ, 2011. p.65-83.

COAN, R.M. et al. Composição bromatológica das silagens de forrageiras de inverno submetidas ou não ao emurchecimento e ao uso de aditivos. ARS Veterinária, v.17, n.1, p.58-63, 2001. Disponível em: <http://www.arsveterinaria.org.br/arquivo/2001/-v.17,\%20n.1,\%20 2001/58-63.pdf>. Acesso em: 30 maio. 2013.

EVANGELISTA, A.R. et al. Forrageiras não convencionais para silagem - mitos e realidades. In: PEREIRA, O.G. et al. Manejo estratégico da pastagem. SIMPÓSIO SOBRE MANEJO ESTRATÉGICO DA PASTAGEM, 2., 2004, Viçosa, MG. Anais... Viçosa: UFV, 2004. V.2, p.463-507.

FERREIRA, J.J. Estágio de maturação ideal para ensilagem de milho e sorgo. In: CRUZ, J.C. et al. (Ed.). Produção e utilização de silagem de milho e sorgo. Sete Lagoas: EMBRAPA Milho e Sorgo, 2001. Cap.16, p.405-428.

FONTANELI, R.S.; FONTANELI, R.S. Uso e abuso da espectroscopia no infravermelho proximal (NIRS). In: RENNÓ, F.P.; PRADO E SILVA, L.F. SIMPÓSIO INTERNACIONAL AVANÇOS EM TÉCNICAS DE PESQUISA EM NUTRIÇÃO DE RUMINANTES, 2007, Pirassununga, SP. Anais... Pirassununga: USP, 2007. p.160-193.

FONTANELI, R.S.; FONTANELI, R.S. Qualidade de forragem. In: FONTANELI, R.S. et al. Forrageiras para integração lavoura-pecuária-floresta na região Sul-Brasileira. Passo Fundo: Embrapa Trigo, 2009. Cap.1, p.25-31.

FONTANELI, R.S. et al. Rendimento e valor nutritivo de cereais de inverno de duplo propósito: forragem verde e silagem ou grãos. Revista Brasileira de Zootecnia, v.38, n.11, p.21162120, 2009. Disponível em: <http://dx.doi.org/10.1590/S1516-
35982009001100007>. Acesso em: 19 jun. 2013. doi: 10.1590/ S1516-35982009001100007.

FONTANELI, R.S. et al. Rendimento e valor nutritivo de cereais de inverno para silagem. In: REUNIÃO DA COMISSÃO BRASILEIRA DE PESQUISA DE AVEIA, 31., 2011, Passo Fundo, RS. Resultados experimentais... Passo Fundo: RCBPA, 2011. p.186-189.

JOBIM, C.C. et al. Sistemas de produção de leite com ênfase na utilização de volumosos conservados. In: REIS, R.A. et al. (Ed.). Volumosos na produção de ruminantes. Jaboticabal: Funep, 2005. p.61-82.

LOPES, F.C.F. et al. Valor nutricional do triticale (X Triticosecale Wittimack) para uso como silagem na Zona da Mata de Minas Gerais. Arquivo Brasileiro de Medicina Veterinária e Zootecnia, v.60, n.6, p.1484-1492, 2008. Disponível em: <http:// dx.doi.org/10.1590/S0102-09352008000600027>. Acesso em: 19 jun. 2013. doi: 10.1590/S0102-09352008000600027.

MEINERZ, G.R. et al. Silagem de cereais de inverno submetidos ao manejo de duplo propósito. Revista Brasileira de Zootecnia, v.40, n.10, p.2097-2104, 2011. Disponível em: <http://dx.doi. org/10.1590/S1516-35982011001000005>. Acesso em: 19 jun. 2013. doi: 10.1590/S1516-35982011001000005.

MORAES, A.de et al. Avanços científicos em integração lavourapecuária no Sul do Brasil Synergismus scyentifica. UTFPR, v.6, n.2, p.1-9, 2011. Disponível em: <http://revistas.utfpr.edu.br/pb/ index.php/SysScy/article/view/1426>. Acesso em: 19 jun. 2013.

MUCK, R.E. Factors influencing silage quality and other implications for management. Journal of Dairy Science, v.71, p.2292-3002, 1988.

RECH, C.L.de S. et al. Determinação do nitrogênio amoniacal. In: . Análises Bromatológicas e Segurança Laboratorial. Pelotas: UFPel, 2006. p.41-42.

SAS Institute. SAS system for Microsoft Windows version 8.2. Cary, 2003. 554p.

SILVA, D.J.; QUEIROZ, A.C. de. Determinação do pH, da acidez titulável e do ácido lático da silagem. In: ___ ___ (Ed.). Análise de alimentos: métodos químicos e biológicos. 3.ed. Viçosa: UFV, 2002. p.163-168.

STRECK, E.V. et al. Solos do Rio Grande do Sul. 2.ed. Porto Alegre: EMATER/RS-ASCAR, 2008. 222p.

TOMICH, T.R. et al. Características químicas para avaliação do processo fermentativo de silagens: uma proposta para qualificação da fermentação. Corumbá: Embrapa Pantanal, 2003. 20p. (Documentos, 57).

VAN SOEST, P.J. Nutritional ecology of the ruminant. 2.ed. Ithaca, New York: Cornell University, 1994. 476p. 